\title{
Consenso sobre los criterios de legibilidad de los folletos de educación para la salud
}

\author{
Consensus on the legibility criteria of health \\ education leaflets
}

\author{
I.M. Barrio ${ }^{1}$, P. Simón-Lorda ${ }^{2}$, M. Melguizo ${ }^{3}$, A. Molina ${ }^{4}$
}

\section{RESUMEN}

Fundamento. Identificación de los aspectos más relevantes que establecen las recomendaciones sobre la legibilidad folletos de educación para la salud.

Material y métodos. Metodología Delphi con objeto de conseguir entre los expertos un consenso sobre los criterios de legibilidad en el diseño y la edición de folletos de educación para la salud.

Resultados. Diecisiete expertos llegaron a un acuerdo sobre las principales recomendaciones para asegurar la legibilidad de los folletos de educación para la salud. Son las siguientes: a) Sobre el contenido y el diseño del texto: estructurar el texto con títulos, subtítulos, explicación del mensaje y conclusión. b) Sobre la construcción del texto: utilizar frases simples y concisas, ofrecer esquemas y ejemplos, destacando gráficamente las ideas principales; c) Sobre la comprensión léxica: utilizar palabras sencillas y evitar el lenguaje técnico y abreviaturas. d) Sobre la tipografía: usar un tipo de fuente fácil de leer.

Conclusiones. Hay un alto grado de consenso con respecto a cómo deben ser elaborados los folletos de educación para la salud. La lista de recomendaciones podría ser utilizada como instrumento para revisar y mejorar el diseño de materiales de educación para la salud. En general, es necesario implicar a los destinatarios de los folletos a colaborar en la redacción y diseño de los mismos.

Palabras clave. Legibilidad. Método Delphi. Educación para la salud.

\begin{abstract}
Background. To identify the most relevant aspects that guarantee the readability, clarity and simplicity of written health education materials.
\end{abstract}

Material and methods. Delphi methodology in order to reach a state of consensus among health education experts on criteria of legibility in the design and publication of informative material and literature.

Results. Seventeen experts reached agreement on the principal recommendations for ensuring the legibility of health education materials. They were as follows: a) text content and layout: to structure the text using a title or subtitle, message explanation and conclusion; b) text construction: to use simple and concise sentences, diagrams and examples, and graphically highlighting the principal ideas; c) lexical comprehension: to use simple words and avoid technical language and abbreviations; d) typography: to use an easyto-read font.

Conclusions. There is a high degree of consensus regarding the way health education materials should be drawn up. This list of recommendations could be used as an instrument for reviewing and improving the design of health education materials. In general, it is recommended to identify the users of the leaflets and involve them in the writing and design.

Key words. Readability. Delphi method. Health education.

\section{Correspondencia}

Inés $\mathrm{M}^{\mathrm{a}}$ Barrio Cantalejo

Unidad de Gestión del Conocimiento

Hospital de Baza

18800 Baza. Granada

3. Centro de Salud Amanjáyar. Granada.

4. Fundación para Investigación Biosanitaria Alejandro Otero, Granada. 


\section{INTRODUCCIÓN}

La educación para la salud forma parte importante de las tareas de los profesionales sanitarios. El documento Salud para todos actualizado en $2005^{1}$, expresa, como sus precedentes versiones de 1980 y 1998 , la necesidad de fomentar la participación de los ciudadanos en las estrategias de mejora de la salud de la población a través de la educación y la cesión de poderes. La participación activa del público es la vía más efectiva para que la población adopte comportamientos saludables ${ }^{2}$. La participación de los ciudadanos en su propia salud depende de variados factores como la motivación personal, el contexto social, económico y político, la educación y la información. No siendo cada uno de ellos efectivo de forma aislada, la revisión bibliográfica indica que la mejor forma de conseguir la participación del público es proporcionarle información ${ }^{3,4}$. Salud para todos señala que los ciudadanos han de estar bien informados para realizar elecciones adecuadas sobre su salud.

Con frecuencia la información se transmite por escrito, en muchos casos a través de folletos, impresos de reducido número de hojas que sirven de instrumento divulgativo o publicitario. El problema puede surgir cuando estos materiales son difíciles de entender para la población ${ }^{5}$. De esta manera es imposible que cumplan el objetivo para el que fueron diseñados, que es mejorar los conocimientos de las personas, su participación y, en definitiva, sus comportamientos saludables.

En los últimos años la revisión bibliográfica y la investigación biomédica han demostrado un progresivo interés en la legibilidad de los folletos que se entregan a los pacientes ${ }^{6-8}$. Para mejorar la comunicación entre los agentes sanitarios y los pacientes se recomienda diseñar la información de acuerdo con las características de la población ${ }^{9,10}$. Con este objeto, la Agencia Europea de Evaluación de Medicamentos EMEA ha elaborado los requisitos de legibilidad que han de cumplir los prospectos de medicamentos ${ }^{11}$. Igualmente el Manual sobre educación sanitaria en atención primaria de salud de la $\mathrm{OMS}^{12}$, recomienda que los mensajes de salud se transmitan de forma legible. Existe una gran variedad de catálogos de recomendaciones para mejorar la legibilidad de los folletos. Algunos recogen la opinión de los pacientes ${ }^{13}$ o grupos profesionales independientes, como enfermeras ${ }^{14}$, pedia$\operatorname{tras}^{15}$, farmacéuticos ${ }^{16} \mathrm{y}$ dentistas ${ }^{17}$. Otros aplican fórmulas como Flesch Reading Ease Score ${ }^{18}$, Dale-Chall ${ }^{19}$, Fry ${ }^{20}$, Niebla ${ }^{21}$, que analizan algunos aspectos lingüísticos del texto y ninguno tipográfico. Por último, hay una lista de recomendaciones que, siendo una valiosa aportación, no tienen ninguna base empírica ${ }^{22,23}$ y son más bien propuestas intuitivas ${ }^{24,25}$.

Sin embargo, no se ha encontrado ningún trabajo que analice los requisitos de legibilidad en el contexto sanitario español y que, de forma interdisciplinar, recoja la opinión de todos los profesionales implicados en la tarea de educación sanitaria. Tampoco se hallado ningún trabajo que estudie la complementariedad de las dimensiones tipográficas y lingüísticas en la elaboración de materiales educativos sobre salud.

El objetivo del presente estudio es profundizar en los diferentes aspectos que hacen legible un folleto de educación para salud en el contexto sanitario español. El objetivo secundario es formular las recomendaciones para mejorar la legibilidad de los folletos.

\section{MATERIAL Y MÉTODOS}

El estudio se llevó a cabo entre Octubre de 2006 y Noviembre de 2007.

Diseño. El diseño metodológico elegido ha sido la búsqueda de consenso entre un grupo de expertos españoles en educación para la salud, en diseño y elaboración de materiales divulgativos y en lengua y literatura. Se ha buscado identificar las diferentes hipótesis sobre la mejora de la legibilidad de los textos escritos sobre educación para la salud según la experiencia de un grupo de profesionales reconocidos por su trabajo en este tema. 
El proceso de obtención de consenso ha utilizado la técnica Delphi. Es un método desarrollado por la RAND Corporation ${ }^{26}$ en los años 50 para facilitar el acuerdo entre expertos, habitualmente con finalidades prospectivas.

Es un método exploratorio, buscador de consenso, basado en la retroalimentación. Fue diseñado para resolver situaciones de incertidumbre, en las que hay que armonizar opiniones individuales diferentes para llegar a una decisión común de todo un grupo. Entre sus ventajas está su gran capacidad de integrar información y diferentes puntos de vista y de obtener acuerdos entre los participantes. El método permite identificar los matices más sensibles de un tema y las tendencias de las opiniones más cualificadas. La validez de los resultados de un estudio Delphi no se apoya en la representatividad estadística de la muestra sino en la claridad de la definición del tema, en el diseño del cuestionario utilizado y en la selección del panel de expertos con experiencia y opiniones relevantes. Este método ha sido a veces criticado por conseguir el acuerdo entre los expertos debido a la presión del grupo. Para evitar que los expertos renuncien a la defensa de su opinión por armonizarla con la del resto, se han tomado dos medidas: mantener oculta la identidad de los miembros del panel e informar de los desacuerdos expresados en el debate y enviar a cada experto la totalidad de comentarios ofrecidos por el resto. Participantes. A. Grupo asesor: 4 profesionales pertenecientes al ámbito académico de la Salud Pública, conocedores de las estrategias de educación para la salud y de la metodología Delphi, han guiado el estudio durante todas sus fases. Su contribución ha consistido en revisar la literatura y delimitar el campo temático de estudio, diseñar y validar el cuestionario de recogida de datos y constituir el panel de expertos. B. Panel de expertos: Se han seleccionado como panelistas a profesionales expertos en los diferentes aspectos de la legibilidad y de la educación para la salud en el contexto sanitario español. La composición del panel ha buscado garantizar la diversi- dad de formación, ocupación y perspectiva de los diferentes agentes implicados en la legibilidad y en educación para la salud. Se invitó a enfermeras comunitarias, médicos y psicólogos por su experiencia en actividades de educación para la salud; a profesionales del ámbito del marketing y la publicidad por su experiencia en el diseño gráfico de materiales escritos. Finalmente, se invitó a pedagogos y profesores en lengua y literatura española. Se buscó que cada perfil ofreciese visiones complementarias que aportasen al análisis una mayor riqueza de puntos de vista. La tabla 1 muestra el perfil profesional y académico de los miembros.

Tabla 1. Perfil profesional y académico del Panel de Expertos

1. Médica de Familia. Programa de Actividades Comunitarias en Atención Primaria (PACAP). Sevilla.

2. Editor de revista científica. Granada.

3. Experta en Medios de comunicación audiovisual, diseño gráfico. Londres.

4. Enfermera Comunitaria, Responsable de Desarrollo de programas de Educación para la Salud en Atención Primaria. Madrid.

5. Psicóloga, Enfermera, Responsable de Calidad en Atención Primaria. Madrid.

6. Psicóloga, Responsable de Programas de Educación para la Salud, miembro de PACAP. Madrid.

7. Documentalista, Plan Oncológico Andaluz, Responsable de la elaboración de materiales educativos destinados a pacientes oncológicos. Granada.

8. Pedagoga, Técnica de Educación para la Salud en Atención Primaria. (Sevilla).

9. Responsable de Promoción de la Salud e Intervenciones Grupales y Comunitarias. Madrid.

10. Responsable de Educación para la Salud, Atención Primaria. Madrid.

11. Profesora de Lengua y Literatura de Instituto de Enseñanza Secundaria. Madrid.

12. Investigadora, diseñadora de materiales sobre salud dirigidos a pacientes. Granada.

13. Educadora en programas de Educación para la Salud. Madrid.

14. Profesora de Salud Pública, Universidad. Huelva.

15. Profesor de Enfermería Comunitaria. Madrid.

16. Experto en Publicidad y Marketing. Granada.

17. Enfermera comunitaria. (Madrid). 
La identidad del grupo asesor y del panel de expertos se mantuvo en el anonimato hasta dar por finalizado el estudio.

Recogida de datos. Se realizaron tres rondas de consulta rounds. En todas los panelistas recibieron los cuestionarios por correo electrónico y respondieron por esta misma vía.

a. Primera ronda. Se solicitó a los expertos de forma individual la elaboración de una lista de recomendaciones para mejorar la comprensión y la legibilidad de los materiales educativos, basándose en sus conocimientos y su experiencia sobre el tema. La lista de recomendaciones sirvió al grupo asesor para construir el instrumento de recogida de datos que tomó forma de cuestionario. Los ítems del cuestionario se formularon de forma afirmativa para facilitar respuestas matizadas.

b. Segunda ronda. El cuestionario fue enviado a cada miembro del panel de expertos. Se les pidió que valorasen de 0 a 6 , la relevancia de cada recomendación para la elaboración de folletos educativos sobre salud. Se les pidió que pronosticaran si el cumplimiento de cada recomendación mejoraba la comprensión y la legibilidad de los folletos. Los resultados de la segunda ronda fueron analizados por el grupo asesor y se utilizaron para redactar el cuestionario de la tercera ronda.

c. Tercera ronda. El cuestionario elaborado para la tercera ronda eliminó las recomendaciones puntuadas por debajo de 3 porque fueron considerados insuficientemente relevantes para el panel de expertos. Incluyó las puntuaciones en forma de medidas de concentración y dispersión, así como los comentarios de cada panelista a cada recomendación. Se pidió a los panelistas que ratificasen o modificasen su posicionamiento, considerando las puntuaciones y comentarios de los demás expertos.

El grupo asesor determinó que las respuestas a la tercera ronda debían tener una puntuación mínima de 4 para considerar relevante una recomendación.

\section{RESULTADOS}

La figura 1 recoge el esquema del desarrollo del estudio. En la primera ronda, el cuestionario fue enviado a 20 expertos y respondieron 17 . Los 17 participantes respondieron también en la segunda y tercera ronda. En la primera ronda, los expertos enviaron 98 recomendaciones que fueron clasificadas según afinidades temáticas. Se eliminaron duplicados y se creo un cuestionario estructurado con 61 recomendaciones clasificadas en 5 campos temáticos relacionados con la elaboración de materiales educativos escritos: contenido, legibilidad lingüística, legibilidad tipográfica, edición y proceso de elaboración.

En la segunda ronda cada ítem fue puntuado y comentado por el panel de expertos. En la síntesis de esta ronda se recogió la puntuación media obtenida de cada ítem con su intervalo de confianza. El Grupo Asesor consideró irrelevantes 11 recomendaciones que no alcanzaron una puntuación de 3 y se eliminaron de la lista. 50 recomendaciones integraron el cuestionario de la tercera ronda.

En la tercera ronda los expertos evaluaron de nuevo cada recomendación teniendo en cuenta las puntuaciones y los comentarios de los otros panelistas. El Grupo Asesor eliminó las recomendaciones con puntuación por debajo de 4 . Las tablas 2 al 6 recogen 34 recomendaciones mejor puntuadas. 


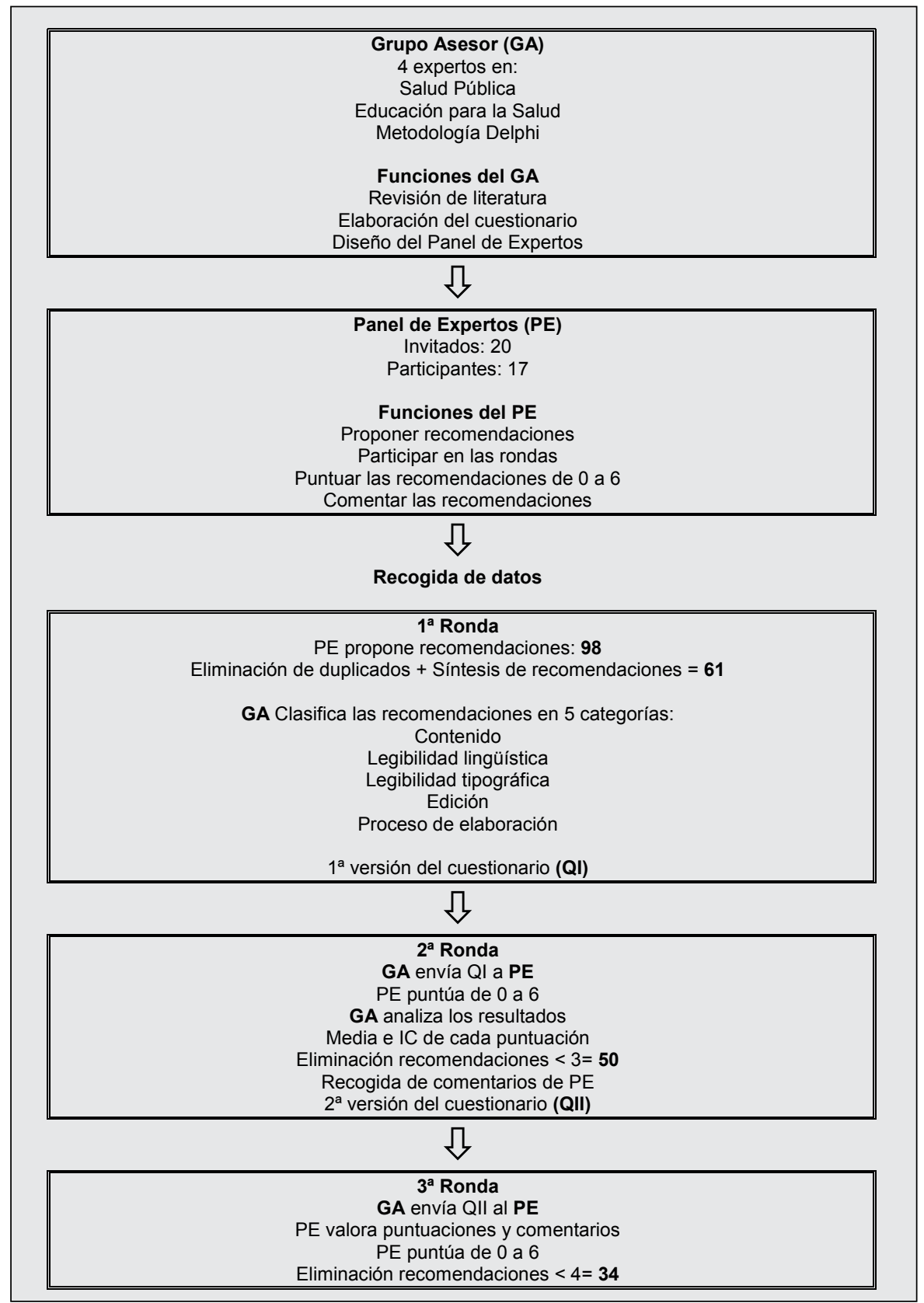

Figura 1. Esquema del desarrollo del estudio. 
Tabla 2. Puntuación e indicaciones de los expertos sobre contenido de los folletos

\begin{tabular}{|c|c|c|c|}
\hline Recomendación & M & IC(95\%) & Indicaciones \\
\hline $\begin{array}{l}\text { Organizar los } \\
\text { contenidos por } \\
\text { epígrafes y por temas }\end{array}$ & 5,03 & $4,69-5,37$ & $\begin{array}{l}\text { 1. Mejora la comprensión y el aspecto visual. } \\
\text { 2. Evita la fatiga en la lectura. } \\
\text { 3. No fragmentar demasiado el discurso, porque se "pierde el hilo". } \\
\text { 4. Que el texto esté ordenado, facilita su lectura y claridad. } \\
\text { 5. Son necesarios epígrafes que orienten sobre lo que viene a } \\
\text { continuación. } \\
\text { 6. Depende de la extensión del folleto. A más mensajes, mayor } \\
\text { necesidad de fragmentación, pero también mayor necesidad de } \\
\text { nexos de continuidad. }\end{array}$ \\
\hline Ser breves & 5,00 & $5,25-4,75$ & $\begin{array}{l}\text { 1. Precisar cuál es el mensaje principal. } \\
\text { 2. Breve pero que se entienda. } \\
\text { 3. Consensuar el estilo lingüístico antes de iniciar la redacción para } \\
\text { garantizar la unidad formal. } \\
\text { 4. Concisión y información suficiente. } \\
\text { 5. Si algo se puede decir con } 5 \text { palabras, no usar } 6 \text {. } \\
\text { 6. Redactar el texto con concisión y brevedad. } \\
\text { 7. Evitar exponer muchos mensajes juntos. Si hay muchas ideas, mejor } \\
\text { hacer varios folletos. } \\
\text { 8. Precisar el mensaje que se quiere transmitir. } \\
\text { 9. No hacer digresiones que ahoguen lo importante en un mar de } \\
\text { nimiedades. } \\
\text { 10. El lector debe distinguir claramente el mensaje principal de los } \\
\text { mensajes secundarios. }\end{array}$ \\
\hline $\begin{array}{l}\text { Si el texto recoge } \\
\text { muchas ideas, } \\
\text { agruparlas bajo una } \\
\text { idea común }\end{array}$ & 4,47 & $4,00-4,94$ & $\begin{array}{l}\text { 1. Ayuda a centrar ideas y relacionarlas. } \\
\text { 2. Hay que intentar que no sea larga, porque los lectores se pierden. } \\
\text { 3. El folleto debe trasmitir ideas clave: hay que agrupar diferentes } \\
\text { ideas en ideas clave. }\end{array}$ \\
\hline $\begin{array}{l}\text { Terminar el texto con } \\
\text { un pequeño resumen } \\
\text { de las ideas más } \\
\text { importantes }\end{array}$ & 4,41 & $3,94-4,87$ & $\begin{array}{l}\text { 1. Un resumen final ayuda a recordar el mensaje cuando el texto es } \\
\text { largo. } \\
\text { 2. El resumen debe recoger las ideas principales ya expresadas. No } \\
\text { debe ampliar la información ni introducir temas nuevos. } \\
\text { 3. Sintetizar en varias frases las ideas más relevantes del texto. } \\
\text { 4. Que los propios destinatarios elaboren ese resumen. } \\
\text { 5. Dado las dificultades de muchos para leer, un resumen puede } \\
\text { ayudar. } \\
\text { 6. A más texto, mayor necesidad de resaltar las ideas principales }\end{array}$ \\
\hline $\begin{array}{l}\text { Añadir ejemplos } \\
\text { prácticos que } \\
\text { faciliten la } \\
\text { comprensión del } \\
\text { texto }\end{array}$ & 4,41 & $3,94-4,87$ & $\begin{array}{l}\text { 1. Ilustrar con ejemplos prácticos, fundamentalmente con jóvenes. } \\
\text { 2. Ofrecer ejemplos prácticos para ilustrar los conceptos complejos. } \\
\text { 4. Trabajar el folleto en sesiones grupales para mejorar la } \\
\text { comprensión. } \\
\text { 5. Utilizar la analogía para aclarar conceptos complejos } \\
\text { 6. Cuidar la elección de ejemplos evitando ejemplos pueriles o } \\
\text { redundantes que ofendan a la inteligencia del lector. }\end{array}$ \\
\hline $\begin{array}{l}\text { Situar las frases } \\
\text { importantes al } \\
\text { comienzo del párrafo }\end{array}$ & 4,16 & $3,62-4,69$ & $\begin{array}{l}\text { 1. Resaltar al principio las ideas más importantes que se van a } \\
\text { desarrollar. }\end{array}$ \\
\hline $\begin{array}{l}\text { Situar las palabras } \\
\text { importantes al } \\
\text { comienzo de la frase }\end{array}$ & 4,06 & $3,51-4,61$ & $\begin{array}{l}\text { 1. Sobre todo si el texto es largo las palabras que contienen las ideas } \\
\text { más importantes hay que situarlas al principio de la frase. } \\
\text { 2. Además de colocarlas al principio, hay que resaltarlas. }\end{array}$ \\
\hline
\end{tabular}


Tabla 3. Puntuación e indicaciones de los expertos sobre la legibilidad lingüística de los folletos

\begin{tabular}{|c|c|c|c|}
\hline Recomendación & M & IC(95\%) & Indicaciones \\
\hline $\begin{array}{l}\text { No utilizar } \\
\text { abreviaturas }\end{array}$ & 5,69 & $5,39-5,98$ & $\begin{array}{l}\text { 1. A veces no se conoce el significado de las abreviaturas. } \\
\text { 2. Explicarlas las abreviaturas antes de utilizarlas. } \\
\text { 3. Depende del nivel cultural al que vaya dirigido el folleto. } \\
\text { 4. Usar sólo abreviaturas que estén muy popularizadas. }\end{array}$ \\
\hline $\begin{array}{l}\text { No usar dobles } \\
\text { negaciones }\end{array}$ & 5,66 & $5,36-5,95$ & 1. Se entienden con dificultad. \\
\hline $\begin{array}{l}\text { Evitar tecnicismos } \\
\text { sustituirlos por } \\
\text { descripciones } \\
\text { simples }\end{array}$ & 5,56 & $5,25-5,87$ & $\begin{array}{l}\text { 1. Usar tecnicismos acompañados de descripciones simples. } \\
\text { 2. El lenguaje técnico no es exclusivo del profesional. Se pueden } \\
\text { incluir lenguaje técnico sencillo, adaptado al grupo al que se dirige. } \\
\text { 3. Si se utilizan, hacerlo acompañado de una descripción } \\
\text { comprensible. }\end{array}$ \\
\hline $\begin{array}{l}\text { Escribir con } \\
\text { palabras sencillas, } \\
\text { pero no vulgares }\end{array}$ & 5,44 & $5,13-5,75$ & $\begin{array}{l}\text { 1. Utilizar palabras de significado conocido. } \\
\text { 2. Sencillas pero precisas. } \\
\text { 3. Evitar términos vulgares aunque sean habitualmente utilizados por } \\
\text { la población. } \\
\text { 4. Presentar al comienzo de un texto las diferentes denominaciones de } \\
\text { un concepto. A partir de ahí, utilizar el más correcto. }\end{array}$ \\
\hline $\begin{array}{l}\text { No usar, en lo } \\
\text { posible, frases } \\
\text { compuestas, con } \\
\text { subordinadas }\end{array}$ & 4,66 & $4,16-5,15$ & $\begin{array}{l}\text { 1. No se debe utilizar más de una frase subordinada. } \\
\text { 2. Convertir cada oración subordinada en oraciones simples. } \\
\text { 3. A veces las oraciones subordinadas son útiles para concatenar } \\
\text { ideas y no perder el hilo. En tal caso, usar un lenguaje directo y } \\
\text { llano. }\end{array}$ \\
\hline $\begin{array}{l}\text { Usar la voz activa } \\
\text { mejor que la pasiva }\end{array}$ & 4,56 & $4,00-5,13$ & 1. La voz pasiva se utiliza poco en el lenguaje coloquial. \\
\hline $\begin{array}{l}\text { Escribir una idea } \\
\text { por párrafo }\end{array}$ & 4,50 & $3,97-5,03$ & 1. Sobre todo si el folleto expone un contenido complejo. \\
\hline $\begin{array}{l}\text { Escribir con frases } \\
\text { cortas, de no más } \\
\text { de } 10 \text { palabras. }\end{array}$ & 4,38 & $4,07-4,68$ & $\begin{array}{l}\text { 1. Explicar los conceptos sanitarios difíciles con frases cortas. } \\
\text { 2. Evitar que las frases cortas parezcan órdenes. } \\
\text { 3. Siempre que incluya lo más importante. }\end{array}$ \\
\hline $\begin{array}{l}\text { Usar el punto para } \\
\text { separar frases, } \\
\text { evitando el punto } \\
\text { y coma }\end{array}$ & 4,31 & $3,73-4,90$ & 1. Son preferibles los puntos y los puntos y aparte. \\
\hline
\end{tabular}


Tabla 4. Puntuación e indicaciones de los expertos sobre la legibilidad tipográfica de los folletos

\begin{tabular}{|c|c|c|c|}
\hline Recomendación & M & $\mathrm{IC}(95 \%)$ & Indicaciones \\
\hline $\begin{array}{l}\text { Destacar } \\
\text { gráficamente las } \\
\text { palabras y frases } \\
\text { importantes }\end{array}$ & & & $\begin{array}{l}\text { 1. El lector tiene que descubrir de un golpe de vista lo más importante } \\
\text { que se le quiere transmitir. } \\
\text { 2. Señalar en negrita, mayor tamaño o cambio de letra los mensajes más } \\
\text { significativos. } \\
\text { 3. La homogeneidad tipográfica en el texto escrito se asocia con la } \\
\text { homogeneidad en relevancia del contenido. Conviene destacar las } \\
\text { ideas clave con elementos tipográficos que rompan la uniformidad y } \\
\text { llamen la atención del lector. }\end{array}$ \\
\hline $\begin{array}{l}\text { Usar tipos de } \\
\text { letra fáciles de } \\
\text { leer. Muchos son } \\
\text { impactantes, pero } \\
\text { difíciles de leer }\end{array}$ & 5,41 & $5,17-5,65$ & $\begin{array}{l}\text { 1. Hay que considerar a las personas mayores con problemas de visión. } \\
\text { 2. Usar letra impactante en los epígrafes y una neutra en el cuerpo de } \\
\text { texto. } \\
\text { 3. Evitar los tipos de letra que son impactantes, pero difíciles de leer. }\end{array}$ \\
\hline $\begin{array}{l}\text { No emplear más de } 2 \\
\text { ó } 3 \text { tipos de letra }\end{array}$ & 5,13 & $4,82-5,43$ & $\begin{array}{l}\text { 1. No es recomendable usar más de dos tipos de letras, sino el lector se } \\
\text { distraerá del contenido. } \\
\text { 2. Jugar con los diferentes grosores (bold, black, médium, roman). }\end{array}$ \\
\hline $\begin{array}{l}\text { Evitar el exceso de } \\
\text { imágenes con sólo } \\
\text { función ornamental }\end{array}$ & 5,03 & $4,52-5,54$ & $\begin{array}{l}\text { 1. Usar la imagen como apoyo al contenido, no como adorno. } \\
\text { 1. Escoger una imagen que invite a leer el texto. } \\
\text { 2. El exceso de ornamentos puede cansar y despistar de lo esencial del } \\
\text { mensaje. }\end{array}$ \\
\hline $\begin{array}{l}\text { Utilizar un tamaño } \\
12 \text { de letra cómo } \\
\text { mínimo. Lo ideal es } \\
13 \text { ó } 14\end{array}$ & 4,97 & $4,61-5,33$ & $\begin{array}{l}\text { 1. Mejor el } 14 . \\
\text { 2. Entre el } 12 \text { y el } 13 .\end{array}$ \\
\hline $\begin{array}{l}\text { No escribir por } \\
\text { entero mensajes con } \\
\text { letra mayúscula }\end{array}$ & 4,94 & $4,48-5,39$ & $\begin{array}{l}\text { 1. Los mensajes escritos por entero con letras mayúsculas son difíciles } \\
\text { de leer. }\end{array}$ \\
\hline $\begin{array}{l}\text { Utilizar imágenes } \\
\text { que aclaren en el } \\
\text { contenido }\end{array}$ & 4,94 & $4,60-5,27$ & $\begin{array}{l}\text { 1. A veces las imágenes explican más que el propio texto. } \\
\text { 2. Que sean esquemáticas y sencillas. } \\
\text { 3. Imágenes en relación directa con el texto y no un mero adorno. }\end{array}$ \\
\hline $\begin{array}{l}\text { Evitar los fondos } \\
\text { con dibujos, texto } \\
\text { sobreimpreso o } \\
\text { marcas de agua }\end{array}$ & 4,81 & $4,40-5,22$ & $\begin{array}{l}\text { 1. Los fondos de dibujo dificultan la lectura. } \\
\text { 2. Las marcas de agua no añaden nada al mensaje y pueden distraer. } \\
\text { 3. Explorar nuevas formas de destacar un texto sobre el fondo. }\end{array}$ \\
\hline $\begin{array}{l}\text { Utilizar con } \\
\text { moderación la } \\
\text { negrita, subrayados y } \\
\text { cursivas. Usarlos sólo } \\
\text { en mensajes muy } \\
\text { importantes }\end{array}$ & 4,75 & $4,37-5,13$ & $\begin{array}{l}\text { 1. La negrita es adecuada. Las cursivas son menos legibles. } \\
\text { 3. Usarlas para resaltar palabras. } \\
\text { 4. No abusar, utilizarlas sólo para destacar lo importante. } \\
\text { 5. Dar un valor a cada recurso tipográfico y utilizarlo de forma uniforme } \\
\text { en todo el texto. } \\
\text { 6. Mejor sólo negrita para encabezamientos o palabras importantes. }\end{array}$ \\
\hline $\begin{array}{l}\text { Dejar espacios en } \\
\text { blanco en la página, } \\
\text { para que la vista } \\
\text { descanse }\end{array}$ & 4,50 & $4,06-4,94$ & 1. Los folletos deben ser dejar espacios de descanso para la vista. \\
\hline $\begin{array}{l}\text { Evitar los fondos } \\
\text { oscuros sobre los que } \\
\text { vaya texto }\end{array}$ & 4,50 & $3,81-5,19$ & $\begin{array}{l}\text { 1. El fondo oscuro cansa más la vista. } \\
\text { 2. Evitar diseños que no aporten nada a la comunicación. }\end{array}$ \\
\hline $\begin{array}{l}\text { Evitar los negativos } \\
\text { (fondo oscuro y } \\
\text { letras claras) }\end{array}$ & 4,31 & $3,60-5,02$ & $\begin{array}{l}\text { 1. Cansan la vista. } \\
\text { 2. Son caros. }\end{array}$ \\
\hline $\begin{array}{l}\text { Escribir en letras } \\
\text { negras sobre fondo } \\
\text { blanco o de color } \\
\text { muy claro }\end{array}$ & 4,00 & $3,33-4,67$ & $\begin{array}{l}\text { 1. Mejor usar un color tenue y relajante. } \\
\text { 2. La elección del color debe buscar la unidad y la limpieza. } \\
\text { 3. Mejor un color de fondo que resalte el texto. }\end{array}$ \\
\hline
\end{tabular}


Tabla 5. Puntuación e indicaciones de los expertos sobre la edición de los folletos

\begin{tabular}{|c|c|c|c|}
\hline Recomendación & M & IC(95\%) & Indicaciones \\
\hline $\begin{array}{l}\text { Intentar que la obra } \\
\text { final sea breve }\end{array}$ & 5,44 & $5,04-5,84$ & $\begin{array}{l}\text { 1. La brevedad junto con la claridad en la exposición es la clave de la } \\
\text { lectura de los folletos. } \\
\text { 2. Los folletos de muchas páginas están condenados al abandono de su } \\
\text { lectura. }\end{array}$ \\
\hline $\begin{array}{l}\text { Presentar con } \\
\text { claridad la secuencia } \\
\text { de lectura de los } \\
\text { folletos con varios } \\
\text { dobleces (trípticos, } \\
\text { por ejemplo) }\end{array}$ & 5,41 & $5,01-5,80$ & $\begin{array}{l}\text { 1. La mejor presentación es un cuadernillo con páginas numeradas. } \\
\text { 3. Si hay dobleces, señalar con flechas o números la secuencia de } \\
\text { lectura. }\end{array}$ \\
\hline $\begin{array}{l}\text { Mostrar márgenes } \\
\text { del documento } \\
\text { suficientemente } \\
\text { amplios }\end{array}$ & 5,38 & $4,98-5,77$ & $\begin{array}{l}\text { 1. Evitar que dobleces, grapas o cosidos del documento "se coman» las } \\
\text { letras. }\end{array}$ \\
\hline $\begin{array}{l}\text { Es preferible elaborar } \\
\text { varios folletos sobre } \\
\text { diferentes temas } \\
\text { relacionados entre sí } \\
\text { que un único material } \\
\text { que aborde todos los } \\
\text { temas }\end{array}$ & 4,66 & $4,18-5,14$ & $\begin{array}{l}\text { 1. Preferible elaborar varios folletos si son temas con entidad suficiente. } \\
\text { Unificar el formato de los que tengan una temática relacionada. El } \\
\text { profesional puede usarlos en un proceso educativo evitando dar un } \\
\text { material demasiado extenso. } \\
\text { 2. Preferible ajustar el contenido informativo a las necesidades del } \\
\text { interlocutor, evitando dar lo que no necesita. } \\
\text { 7. Los temas relacionados con la esfera psicosocial y de conductas, es } \\
\text { preferible abordarlos con un único material y con un único texto. En } \\
\text { estos temas, el fraccionamiento puede hacer menos comprensible el } \\
\text { contenido. } \\
\text { 4. Si queremos difundir información es mejor tener varios folletos que } \\
\text { apoyen cada momento del proceso de enseñanza. } \\
\text { 9. Planificar una serie. Explicitar el sumario en la contraportada de cada } \\
\text { folleto. Hacer referencia a los contenidos de otros folletos de la serie } \\
\text { para mantener la coherencia y el hilo argumental. }\end{array}$ \\
\hline $\begin{array}{l}\text { No utilizar papeles } \\
\text { muy satinados, } \\
\text { que produzcan } \\
\text { brillos molestos } \\
\text { que impidan la fácil } \\
\text { lectura }\end{array}$ & 4,41 & $3,88-4,94$ & $\begin{array}{l}\text { 1. Parece una cuestión menor pero es realmente fastidioso. } \\
\text { 2. El brillo en diseño se considera un estilo obsoleto de los años } 80 \text {. }\end{array}$ \\
\hline
\end{tabular}

Tabla 6. Puntuación e indicaciones de los expertos sobre el proceso de elaboración de los folletos

\begin{tabular}{|l|c|c|c|}
\hline \multicolumn{1}{|c|}{ Recomendación } & M & IC(95\%) & \multicolumn{1}{c|}{ Indicaciones } \\
\hline $\begin{array}{l}\text { Hacer de la } \\
\text { elaboración del } \\
\text { material un proceso } \\
\text { participativo: }\end{array}$ & 5,28 & $4,90-5,66$ & $\begin{array}{l}\text { 1. Para poder reconocer los intereses de los participantes. } \\
\text { 2. La participación del grupo al que se dirige da claves para el } \\
\text { contenidos como para la presentación. }\end{array}$ \\
$\begin{array}{l}\text { Invitar a los } \\
\text { destinatarios } \\
\text { del material a } \\
\text { que colaboren } \\
\text { en el proceso de } \\
\text { redacción y diseño } \\
\text { del mismo }\end{array}$ & & $\begin{array}{l}\text { 3. Antes de la impresión y difusión, asegurar que el material se } \\
\text { comprende, que responde a las dudas de los destinatarios y que se } \\
\text { adecua a su competencia lingüística. }\end{array}$ \\
& & $\begin{array}{l}\text { 4. Garantizar la función didáctica del material. } \\
\text { 5. Los profesionales tienen conocimientos técnicos y la población la } \\
\text { experiencia cotidiana en salud y enfermedad. Un proceso conjunto } \\
\text { obtendrá los mejores frutos. }\end{array}$ \\
& & $\begin{array}{l}\text { 6. Un mensaje institucional requerirá la participación de los } \\
\text { destinatarios para verificar la comprensión del mensaje. }\end{array}$ \\
\hline
\end{tabular}


Las recomendaciones más significativas del panel de expertos se pueden resumir de la siguiente manera:

\section{Sobre el contenido}

1. Organizar el contenido por epígrafes y temas. El texto debe ir fragmentado según los diferentes temas que trata. Iniciar cada fragmento con un pequeño título.

2. Ser breves en la exposición de ideas.

3. Si el texto recoge muchas ideas, agruparlas en una idea común.

4. Terminar el texto con un resumen de las ideas más importantes.

5. Añadir ejemplos prácticos e ilustraciones que faciliten la comprensión del texto. Utilizar la analogía para aclarar conceptos complejos.

6. Situar la frase más importante al comienzo del párrafo. En los párrafos posteriores se pueden ampliar explicaciones que profundicen en el tema.

7. Situar las palabras importantes al comienzo de cada frase.

\section{Sobre la legibilidad lingüística del texto}

1. No utilizar abreviaturas.

2. No utilizar la doble negación.

3. Evitar tecnicismos: sustituirlos por descripciones simples.

4. Escribir con palabras sencillas.

5. Construir frases simples. Evitar las frases compuestas con más de una oración subordinada.

6. Emplear la voz activa mejor que la pasiva.

7. Escribir una idea por párrafo.

8. Redactar frases cortas, de diez palabras como máximo.

9. Usar el punto para separar frases, evitando el punto y coma.

10. Ofrecer ejemplos prácticos que ilustren conceptos complejos.

\section{Sobre la legibilidad tipográfica}

1. Destacar gráficamente las palabras y frases importantes.

2. Usar tipos de letra fáciles de leer.

3. No emplear más de dos o tres tipos de letra.

4. Evitar la sobrecarga de imágenes que tengan sólo función ornamental.

5. Usar un tamaño 12 de letra como mínimo. Lo ideal es 13 ó 14.

6. No escribir por entero mensajes con letras mayúsculas.

7. Evitar los fondos con dibujos, texto sobreimpreso o marcas de agua.

8. Utilizar con moderación la negrita, subrayados y cursivas, sólo en mensajes muy importantes.

9. Dejar espacios en blanco en la página, para que la vista descanse.

10. Evitar fondos de texto oscuros.

11. Evitar los negativos (fondo oscuro y letras claras).

12. Escribir en letras negras sobre fondo blanco o de color muy claro.

\section{Sobre la edición de folletos}

1. Intentar que la obra final sea breve.

2. Presentar con claridad la secuencia de lectura de los folletos con varios dobleces.

3. Mostrar márgenes del documento suficientemente amplios.

4. Elaborar varios folletos sobre temas relacionados entre sí que un único y extenso folleto que aborde todos los temas.

5. No utilizar papeles muy satinados que produzcan brillos molestos que impidan la fácil lectura.

\section{Sobre el proceso de elaboración de los folletos}

Invitar a los destinatarios de los folletos a colaborar en el proceso de redacción y diseño de los mismos. 


\section{DISCUSIÓN}

Los resultados de este estudio son similares a los que ofrecen otros trabajos sobre legibilidad. Así, las recomendaciones de Cardinal y Martin ${ }^{22}$ de Aldridge $^{23}$ o de Monsiváis y Reynolds ${ }^{24}$ son parecidos a los obtenidos en este estudio. Nuestros resultados también coinciden con las recomendaciones clásicas, como los «Diez Principios de la escritura clara" de Gunning ${ }^{21} \mathrm{o}$ las tipográficas de Richaudeau ${ }^{25}$. El SAM de Doak $^{10}$ y BIDS de Bernier ${ }^{6}$ también ofrecen análogas conclusiones.

En general, los autores desarrollan estas listas combinando recomendaciones tomadas de otros autores o generadas por ellos mismos, basándose en su propia experiencia. Estas recomendaciones raramente poseen base empírica. Sí tiene base empírica, por el contrario, el estudio de Mansoor $^{27}$. Este autor recomienda la inclusión de imágenes explicativas para mejorar la legibilidad. Este ensayo clínico aleatorizado realizado en sudafricanos de bajo nivel académico, concluye que la incorporación de imágenes en los folletos informativos sobre el tratamiento con nistatina, mejora la comprensión de la información y la adherencia al tratamiento sobre el grupo control.

Sin embargo, el estudio del canadiense Hawng $^{28}$, desarrollado en un contexto de cultura y características lingüísticas y cognitivas muy diferentes al de Mansoor concluyó que la incorporación de imágenes en los folletos sobre el uso de medicamentos no mejoró la comprensión de la información en 130 pacientes de Toronto.

Sobre la recomendación de brevedad del texto, el estudio de Sharp ${ }^{29}$ llegó a la conclusión de que un formulario de consentimiento informado para la investigación no debe ser mayor de 1.250 palabras. Sharp afirma que un adulto no va a leer un texto técnico de más de 1.000 palabras, tarea en la que emplearía al menos unos 5-7 minutos. La evidencia que apoya esta recomendación no proviene sino de la opinión la autorizada de expertos.

Por último, el consenso del panel de expertos insiste, como el trabajo de Dic- kinson $^{30}$, en que la participación de los pacientes en el diseño y elaboración de los folletos puede mejorar en gran medida la legibilidad de los mismos.

Las recomendaciones extraídas en el presente estudio y recogida en tablas 2-6 tienen una evidencia empírica sólida. Sin embargo, no son arbitrarias y se basan en el consenso de expertos en diferentes aspectos de la legibilidad y de la educación para la salud.

El estudio tiene dos limitaciones: el método Delphi a veces es sospechoso de producir acuerdos debido a la presión del grupo. Algunos expertos pueden renunciar a la defensa de su opinión en un intento de armonizarla con las contrarias. En nuestro caso, los desacuerdos han sido recogidos como comentarios, devueltos al grupo de debate e incluidos en el consenso final. En segundo lugar, el sesgo potencial de los participantes según su procedencia o diferente sensibilidad y el riesgo de no considerar los aspectos importantes de la legibilidad. Esto se ha tratado de evitar con la composición de un panel heterogéneo desde el punto de vista profesional y académico.

El carácter exploratorio del estudio no permite que sus hallazgos se puedan generalizar ni extraer de ellos conclusiones irrefutables. Para que los resultados puedan ser generalizados son necesarios nuevos estudios. Sin embargo, sí permiten señalar las tendencias de opinión y un importante nivel de acuerdo sobre la legibilidad de los folletos de educación para la salud. Esta contribución puede servir como instrumento de revisión y mejora en el diseño de materiales de educación para la salud.

\section{Agradecimientos}

Este proyecto se ha beneficiado del asesoramiento y las recomendaciones del Departamento de Medicina Preventiva y Salud Pública de la Facultad de Medicina de la Universidad Autónoma de Madrid, especialmente de Ángel Otero Puime y José Ramón Banegas Banegas, profesores 
del Departamento. Igualmente, los autores expresan su agradecimiento a Magdalena Banegas, Matilde Jordán Martín, Manuel Amezcua, Carmen Martín Madrazo, $\mathbf{M}^{\mathbf{a}}$ Asunción Cañada Dorado, Carmen Domínguez Nogueira, Carlos Bermejo Caja, Carmen Herrera Espiñeira, Elena Aguiló Pastrana, Manuela Medina Fernández, Esther Nieto Blanco, Sofía Guerra, Maribel Martín Martín, María Girbés Fontana, Mํㅡ Valle López Santos, Isabel Escalona Labella y Julia Domínguez Bidagor por su colaboración en el desarrollo de este estudio.

\section{BIBLIOGRAFÍA}

1. World Health Organisation. Health for all policy framework for the WHO European Region: 2005 update. Copenhagen: WHO, 2006.

2. Virtanen H, Leino-KilPI H, Salanterä S. Empowering discourse in patient education. Patient Education and Counseling 2007, 662:140-146.

3. Siegel M. Marketing Public Health: Strategies to Promote Social Change. Toronto, Jones \& Bartlett Publishers 2007.

4. Entwistle VA, Watt IS. Patient involvement in treatment decision-making: The case for a broader conceptual framework. Patient Education and Counseling 2006; 633: 268-278.

5. Barrio-Cantalejo IM, Simón-Lorda P, Melguizo M, Escalona IM, MariJuÁn MI, Hernando P. Validación de la Escala INFLESZ para evaluar la legibilidad de los textos dirigidos a pacientes. An Sist San Navarra 2008: 31: 135-152.

6. BERNIER MJ. Establishing the psychometric properties of a scale for evaluating quality in printed education materials. Patient Educ Couns 1996; 29: 283-299.

7. Idoate García VM. La comprensibilidad del consentimiento informado. An Sist San Navarra 2000; 23: 109-113.

8. Gost Garde J, Silvestre C, Ezpeleta P, Astier P, Díaz de Rada O, Artázcoz MT. Evaluación de la práctica clínica del Consentimiento Informado en los ensayos clínicos. An Sist San Navarra 2003 ; 26 : 35-42.

9. Houts PS, Doak CC, Doak LG, Loscalzo MJ. The role of pictures in improving health communication: A review of research on attention, comprehension, recall, and adherence. $\mathrm{Pa}-$ tient Education and Counseling. 2006; 612: 173-190.
10. IdoAte García VM. La utilización de los cuestionarios para la valoración psicosocial de las lumbalgias. An Sist San Navarra 1997; 20: 337-345.

11. European Commission. Guideline on the readability of the label and package leaflet of medicinal products for human use. Brussels WHO, 2006.

12. World Health Organisation. Education for Health: Manual on Health Education in Primary Health Care Geneva: WHO, 1989: 30.

13. Hoffmann T, McKenna K. Analysis of stroke patients' and carers' reading ability and the content and design of written materials: Recommendations for improving written stroke information. Patient Education and Counseling 2006; 63: 286-293.

14. QuiRK P. Screening for Literacy and Readability: Implications for the Advanced Practice Nurse. Clin Nurse Spec 2000; 141: 26-32.

15. FREDA MC. The readability of American Academy of Pediatrics patient education brochures. J Pediatr Health Care 2005; 193: 151156.

16. SANSGIRY SS, CADY PS, PATIL S. Readability of over-the-counter medication labels. J Am Pharm Assoc 1997; 375: 522-528.

17. Hendrickson RL, Huebner CE, Riedy CA. Readability of pediatric health materials for preventive dental care. BMC Oral Health 2006; 6 : 14.

18. FLESCH R. How to write, speak and think more effectively. New York: Harper 1958.

19. Chall JS, Dale E. Readability revisited, the new Dale-Chall readability formula. Cambridge, MA:Brookline Brooks 1995.

20. FRY EB. Fry's readability graph: Clarifications, validity, and extension to level 17. Journal of Reading 1977; 213: 242-252.

21. Gunning R. The technique of clear writing. New York: McGraw-Hill 1952.

22. Cardinal BJ, Martin JJ, Sachs ML. Readability of written informed consent forms used in exercise and sport psychology research. Res Q Exerc Sport 1996; 673: 360-362.

23. AldRIDGE MD. Writing and designing patient education materials. Nephrol Nursing J 2004; 314: 373-377.

24. Monsivais D, Reynolds A. Developing and evaluating Patient Education Materials. Journal of continuing Education Nursing 2003; 344: 172-176.

25. Richaudeau F. La lisibilité. Paris:CEPL/Retz, $1973 \mathrm{p} 11$. 
26. Bas Amorós E. La Planificación por Escenarios: una técnica de análisis exploratorio para el diseño de Estrategias. Anales de Economía y Administración de Empresas 1997; 5: 77-87.

27. MANSOOR LE, DowsE R. Effect of pictograms on readability of patient information materials. Ann Pharmacother 2003; 377-8: 1003-1009.

28. Hwang SW, Tram CQ, Knarr N. The effect of illustrations on patient comprehension of medication instruction labels. BMC Fam
Pract 2005; 61:26. Edición electrónica. http:// www.biomedcentral.com/1471-2296/6/26

29. SHARP SM. Consent documents for oncology trials: does anybody read these things? Am J Clin Oncol 2004; 276: 570-575.

30. Dickinson D, RaYnor DK, Duman M. Patient information leaflets for medicines: using consumer testing to determine the most effective design. Patient Education and Counseling 2001, 43: 147-159. 